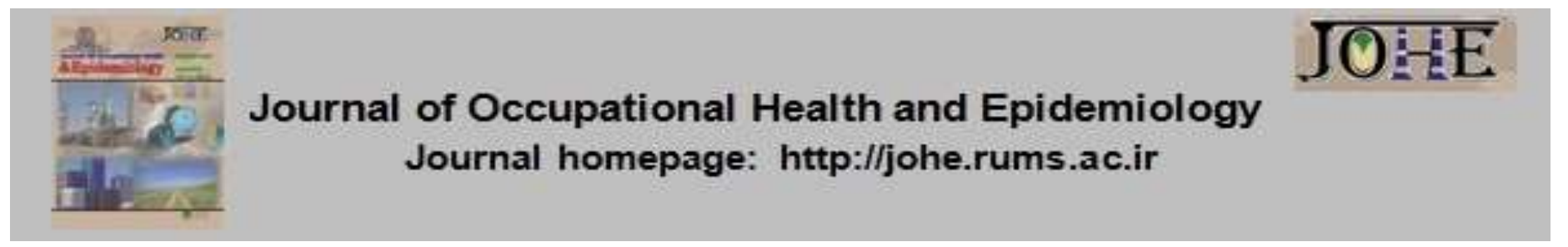

\title{
The association between workload and job stress among nurses in Vasei hospital, Sabzevar city, Iran, in 2016
}

\author{
Mina Madadzadeh¹, Hadith Barati², Akbar Ahmadi Asour ${ }^{3}$ \\ 1- Graduate Student of Occupational Health, Department of Occupational Health, School of Public Health, Sabzevar University of \\ Medical Sciences, Sabzevar, Iran. \\ 2- MSc in Epidemiology, Department of Public Health, School of Public Health, Sabzevar University of Medical Sciences, Sabzevar, \\ Iran. \\ 3- MSc in Occupational Health, Department of Occupational Health, School of Public Health, Sabzevar University of Medical \\ Sciences, Sabzevar, Iran.
}

Citation: Madadzadeh M, Barati H, Ahmadi Asour A. The association between
workload and job stress among nurses in Vasei hospital, Sabzevar city, Iran, in
2016. JOHE. 2018; 7(2):83-9.

Article Info

* Corresponding authors:

Akbar Ahmadi Asour,

E-mail: asour50@yahoo.com

Article history

Received: Aug, 2017

Accepted: Feb, 2018

10.29252/johe.7.2.83

Print ISSN: 2251-8096 Online ISSN: 2252-0902

Peer review under responsibility of Journal of Occupational Health and Epidemiology

\begin{abstract}
Background: Occupations that deal with the health and safety of people are always stressful. Job stress and work load are factors that affect staff such as nurses. The aim of this study was to investigate the association between workload and job stress in nurses of Vasei Hospital, Sabzevar City, Iran, in 2016.

Materials and Methods: This cross- sectional study was conducted on 80 nurses of Vasei Hospital, Sabzevar City based on a probabilistic sampling method. The amount of workload was determined by NASA Task Load Index (NASA-TLX) questionnaire having six dimensions, and job stress was evaluated using Steinmetz questionnaire. Data were analyzed by descriptive tests, analysis of variance and Pearson correlation.

Results: The mean values for work load and job stress were $71.69 \pm 10.49$ and $41.60 \pm$ 10.26 , respectively. $83.8 \%$ of the subjects had high work load ( $>60)$ and $52.5 \%$ of the subjects had moderate stress levels (30-70). The highest mean among six dimensions of workload was related to physical labor $(78.00 \pm 19.97)$, and the lowest mean was related to frustration $(54.75 \pm 20.70)$.

Conclusion: The results did not show a significant association between workload and job stress in the nurses of Vasei Hospital, Sabzevar City. However, the mean work load was high for most people. This situation can be improved by increasing the ability and accountability of nurses through training courses on controlling labor pressure.

Keywords: Workload, Job Stress, Nursing, Iran.
\end{abstract}

\section{Introduction}

One of the factors affecting people in various organizations is occupational stress and workload, which endangers health of individuals (1). As workload is one of the most significant factors in nursing retention, measuring nursing workload reliably is the critical initial step to understanding the relationship between workload, nursing retention and patient safety (2). Workload is the amount of work performed by an entity in a given period of time, or the average amount of work handled by an entity at a particular instant of time. (3). One of the most important problems of nursing is high workload (4). Excessive workload is a major source of stress; in $37 \%$ of subjects high workload of a stressful job has an influence on job dissatisfaction, depression, symptoms Psychosomatic and in 30-50 percent of subjects working in lethargic work environment is a source of stress. Service quality is affected by the imbalance between the number of personnel and the workload of nurses in a hospital. High workload can lead to stress and a decline in the quality of nursing care (5).

Stress is an inevitable part of life (6) Stress has long been recognized as pervasive feature of work 
and there is evidence that it may be increasing in severity (7). Although some stresses are natural and necessary, if severe stress persists or repeats and the person is unable to tolerate it effectively, it will be considered a negative phenomenon that can lead to physical illness and psychiatric disorders (8). Today job stress is one of the most important phenomena in social life; and also a serious threat to the health of the workforce in the world; so that the international labor organization (ILO) has identified occupational stress as the most recognized phenomenon threatening the health of workers (9). Unfavorable physical conditions, physical hazards, workload, time pressure, responsibility of individuals, ambiguity and conflict with colleagues and senior managers or subordinates, constraints, low participation in decision making, and lack of job security are considered as stressful factors in the workplace (10).

Basically, all the professions that are concerned with the health and life of people are stressful, and threaten the physical and mental health of the workers concerned. One of these stressful occupations is nursing because the nurse is the person who is responsible for 24-hour control of the patients and is naturally exposed to many stressful factors. Nursing is a dynamic profession which follows specific ethical rules, and the National Association of Safety Professional (NASP) has introduced nursing at the top of 40 leading careers (11).

Workload and work-related stress affects individuals' safety, health, and comfort; and have a direct relationship with people's performance. Over the past years, workload and its influence on organizations has received considerable attention in discussions related to organizational behavior (10). Workload has been reported to negatively affect the health of employees; long-term diseases may be a result of stress, as well as monotony, mental dullness and fatigue at workplace. Moreover, excessive workload has been ranked first among the reasons for employee burnout, which has been commonly researched in recent years (12).

A descriptive-analytical study was conducted by Zakerian et al. on 200 staff from two large hospitals of Tehran University of Medical Sciences (Imam Khomeini and Shariati hospitals), Tehran, Iran. The data collecting tools were three questionnaires including demographic characteristics, quality of life (SF36), and NASATLX workload. There was a significant inverse relationship between workload and quality of life in hospital staff $(P=0.004)(13)$.

Nurses are faced with a wide range of stressors due to their occupation, and they need to have a high level of skill in teamwork, 24-hour care and bearing emotional load in different situations (11). Hospital nurses and staff are among the highskilled people (14). Responsibility for patient care in nurses and health care providers is associated with increased workload, stress, and feelings of frustration (15).

A cross sectional study was done by Rafiee et al. in Shahid Sadoghi Hospital's Emergency Department in Yazd City, Iran, in 2013. Samples were 17 nurses who were selected through convenience sampling. Data gathered through standardized questionnaire NASA-TLX having 6 domains: physical, mental, time (process work load), performance, trying and frustration (outcome work load) that measured workload in work environment. Findings showed that the mean value in process work load (physical, mental, and time) was 87.34 , and the mean value in outcome work load (trying, performance, and frustration) was 83.28 (16).

Assessing the burden of nurses and health care personnel is necessary according to patient needs (17). The workload is not limited to the physical tasks of the nurses; the nurses' cognitive tasks may also be a complex part of the overall workload (18). Studies show that in work-intensive jobs, due to fatigue and inappropriate scheduling, the performance of individuals and their memory capacity decrease, which lead to damage to the thinking process, and irritability as well as reduction in learning (19). Assessing work load is very important in health care professionals, due to its effects on managing work load and emergency situations. Job stress has direct relationship with the performance and efficiency of individuals (12). The aim of this study was to investigate the relationship between workload and job stress in nurses of Vasei Hospital, Sabzevar City, Iran, in 2016.

\section{Materials and Methods}

This cross- sectional analytical study was done in Vasei Hospital, Sabzevar City during October to December 2016. The target population was nurses of hospital. 80 nurses were selected based on the available method and the following formula in confidence level of $95 \%$.

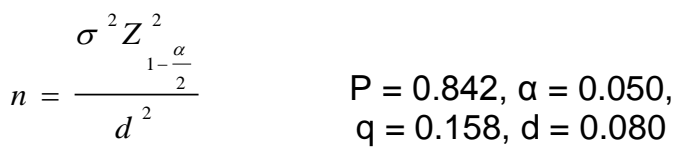


Inclusion criteria were shift working nurses with over one year job experience, and exclusion criteria were history of psychiatric illness. Data collected in two section:

1) demographic data including work experience, gender, working section in hospital, educational level, marital status, and type of employment,

2) NASA-TLX and Steinmetz questionnaires.

First, Steinmetz questionnaire was completed by nurses for assessment of job stress. Steinmetz questionnaire included 36 questions related to job stress. Answers to the questionnaire were measured by five-point Likert scale, in which 1="Never", 2 = "Seldom", 3 = "Often", 4 = "Usually", and $5=$ "Always". The five-point scale was converted to 0-100 scale before data analysis and was divided into three classes: scores lower than 30 (low job stress), scores between $30 \quad-70$ (considerable), and scores over 70 (high job stress) (20). This questionnaire was translated by Attar in 1995 for the first time in Iran. Its validity improved by Hashemzadeh and Orangi study, and its reliability was reported by experimental and test-retest method to be 0.69 and 0.72 , respectively $(P<0.01)(21)$.

NASA Index is one of the well-known tools for assessing workloads that its validity and reliability was reviewed by Hart and Staveland in 1988; and was tested in the study by Mohammadi et al. ( $\alpha=$ 0.897) (20). The questionnaire consists of two general sections. One part is to examine the work load rate and other part determines the importance of each dimension of work load in comparison to other dimensions from the view of participants in the study. This questionnaire evaluated six dimensions including mental work, physical work, time constraints, effort, success rate (performance) and disappointment (frustration). Individuals responding to each of the six dimensions gave a score of zero to one hundred depending on their working conditions (22). Performance and efficiency were assessed by two criteria (good and bad) and other dimensions were evaluated in two levels (low and high). In the second part (15 questions), each of the 6 dimensions was compared pairwise together and marked. The most important and effective item is identified based on person's self report by the analytic hierarchy process (AHP) method (22). After weighting, the overall score of the work load for every person is calculated separately in each of the six dimensions. In many studies, this tool has been used to evaluate the work load. In the study of Mohammadi et al., the validity and reliability of the questionnaire was confirmed (19). In the original version of the NASA -TLX questionnaire, the workload has been set in the range of $0-100$, but there is not a specific range for the level of workload; therefore, according to the working conditions of the nurses and Subjective Workload Assessment Technique (SWAT) questionnaire (a questionnaire for measuring the work load), work load was divided into three levels of low (less than 40 ), moderate (40 to 60) and high (more than 60) (23). In order to find out the relationship between demographic variables with job stress and work load, the data were entered into SPSS software (version 19, SPSS Inc., Chicago, IL, USA) and analysis of variance, t-test, and Pearson correlation test were used.

\section{Results}

80 nurses were selected in this study. The frequency distribution of demographic variables is shown in table 1.

Table 1: Demographic characteristics of Vasei Hospital nurses in Sabzevar City, Iran (2016)

\begin{tabular}{|c|c|c|c|}
\hline \multicolumn{2}{|c|}{ Demographic variables } & \multirow{2}{*}{$\frac{\mathbf{N}}{57}$} & \multirow{2}{*}{$\begin{array}{c}\% \\
71.2\end{array}$} \\
\hline \multirow{2}{*}{ Sex } & Woman & & \\
\hline & Man & 23 & 28.8 \\
\hline \multirow[t]{2}{*}{ Job experience } & $<1$ year & 9 & 11.2 \\
\hline & $1-5$ & 48 & 60.0 \\
\hline \multirow[t]{2}{*}{ (years) } & $5-10$ & 16 & 20.0 \\
\hline & $>10$ & 7 & 8.8 \\
\hline \multirow{4}{*}{ Department } & Neurology & 21 & 26.2 \\
\hline & Internal & 27 & 33.8 \\
\hline & Emergency & 7 & 8.8 \\
\hline & Infectious & 25 & 31.2 \\
\hline \multirow{2}{*}{ Marital status } & Married & 54 & 67.5 \\
\hline & Single & 26 & 32.5 \\
\hline
\end{tabular}


The mean of workload was $71.69 \pm 10.49$ (high level), and job stress mean was $41.60 \pm 10.26$ (moderate level). $83.8 \%$ of nurses had high workload and $16.2 \%$ had moderate level, while
$68.78 \%$ of them had a moderate level of stress, $20.00 \%$ had high level and $11.25 \%$ of nurses had low level of job stress (Figure 1).

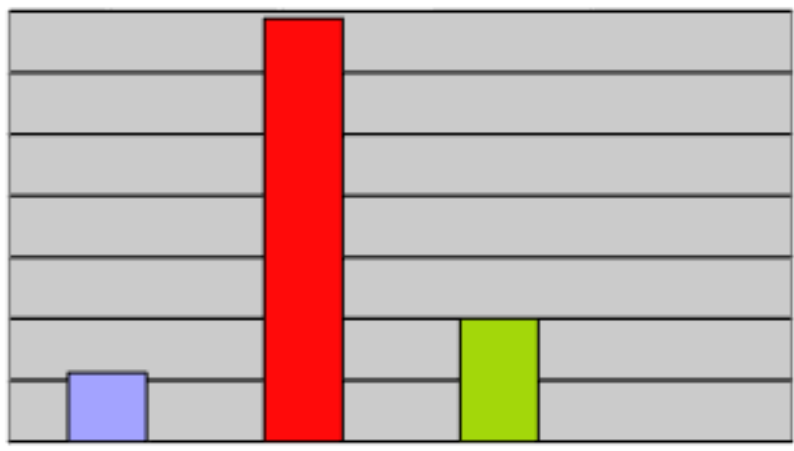

Figure 1: Frequency of job stress levels in nurses of Vasei Hospital, Sabzevar City, Iran (2016)

The mean work load was higher in women than men, in contractual employees than other groups, and in singles than married people. The mean stress in women was more than men; and in people with experience over 10 years was more than other groups. Moreover, those who have been employed in the formal and emergency department had higher stress than employees of other sections. In addition, the mean stress in married and single individuals did not have a significant difference. However, there was no significant relationship between demographic variables, occupational stress and workload as shown in table $2(P>0.05)$.

Table 2: Relationship between work load, job stress, and demographic variables in nurses of Vasei Hospital, Sabzevar City, Iran, in 2016 (analysis of variances and t-test)

\begin{tabular}{|c|c|c|c|c|c|}
\hline \multicolumn{2}{|c|}{ Demographic variable } & Stress & $\mathbf{P}$ & Workload & $\mathbf{P}$ \\
\hline \multirow{2}{*}{ Sex } & Woman & $10.40 \pm 42.20$ & \multirow{2}{*}{0.394} & $62.11 \pm 73.76$ & \multirow{2}{*}{0.141} \\
\hline & Man & $9.79 \pm 40.00$ & & $10.22 \pm 69.62$ & \\
\hline \multirow{2}{*}{ Marital status } & Maried & $11.10 \pm 41.48$ & \multirow{2}{*}{0.881} & $12.00 \pm 72.35$ & \multirow{2}{*}{0.825} \\
\hline & Single & $8.41 \pm 41.84$ & & $9.80 \pm 73.00$ & \\
\hline \multirow{4}{*}{$\begin{array}{c}\text { Work } \\
\text { experience } \\
\text { (years) }\end{array}$} & $<1$ year & $10.92 \pm 42.11$ & \multirow{4}{*}{0.472} & $10.28 \pm 75.10$ & \multirow{4}{*}{0.233} \\
\hline & $1-5$ & $8.96 \pm 41.35$ & & $11.34 \pm 73.71$ & \\
\hline & $5-10$ & $11.76 \pm 40.25$ & & $10.81 \pm 67.41$ & \\
\hline & $>10$ & $15.05 \pm 45.71$ & & $10.28 \pm 75.10$ & \\
\hline \multirow{4}{*}{ Department } & Neurology & $12.30 \pm 42.60$ & \multirow{3}{*}{0.085} & $11.70 \pm 68.85$ & \multirow{4}{*}{0.278} \\
\hline & Internal & $7.16 \pm 37.81$ & & $12.00 \pm 73.62$ & \\
\hline & Emergency & $10.96 \pm 45.71$ & & $14.2 \pm 77.47$ & \\
\hline & Infectious & $10.26 \pm 41.60$ & & $8.85 \pm 73.20$ & \\
\hline
\end{tabular}

The highest score among the six dimensions of work load was $78.90 \pm 19.77$, and the lowest score was $54.75 \pm 20.70$ which was related to frustration dimension. There was not any significant relationship between demographic variables and six dimensions of work load $(P>0.05)$. However, there was a significant relationship between four dimensions including physical, mental, time, and effort dimensions, but no significant relationship was found between efficiency with physical, mental and frustration dimensions (Table 3). 
Table 3: Relationship between workload dimensions in nurses of Vasei Hospital, Sabzevar City, Iran, in 2016 (Pearson correlation test)

\begin{tabular}{|c|c|c|c|c|c|c|}
\hline Variable & Frustration & Efficiency & Effort & Time need & Mental need & $\begin{array}{c}\text { Physical } \\
\text { need }\end{array}$ \\
\hline Physical need & -0.031 & -0.106 & $0.272^{*}$ & $0.333^{* *}$ & $0.426^{* *}$ & 1 \\
\hline Mental need & 0.116 & 0.125 & $0.270^{*}$ & $0.514^{\star *}$ & 1 & \\
\hline Time need & 0.140 & $0.473^{\star *}$ & 0.397 & 1 & & \\
\hline Effort & 0.168 & $0.448^{* *}$ & 1 & & & \\
\hline Efficiency & $-0.024^{*}$ & 1 & & & & \\
\hline Frustration & 1 & & & & & \\
\hline
\end{tabular}

\section{Discussion}

According to the aim of this study, investigation of relationship between workload and job stress in nurses, $83.3 \%$ of respondents reported high workload, and the mean of work load in this study was $69.61 \pm 49.9$. This result can be expected because this hospital is one of the largest public hospitals in the city and a lot of people visit it. In most studies, high work load has been reported among nurses $(11,24)$.

In this study, the mean workload of nurses with one year work experience was higher than other groups, and this difference could be due to the misunderstanding of new employees regarding the different needs of the nursing profession. Nurses of the emergency department had the highest rate of work load, because of different work conditions in comparison to other departments; moreover, time constraints and physical pressure in these nurses were more than other nurses. In the present study, the highest mean in six dimensions of work load was related to physical work load $(78.00 \pm 19.97)$ which can be due to a lot of physical pressure on the nurses during their work. The lowest score was related to frustration with mean value of $54.75 \pm 7.70$, because of the relative satisfaction of nurses regarding their duties in work environment.

In the research by Taheri et al., in Isfahan hospitals, the mean value of mental load dimension was $79.20 \pm 14.60$, while frustration dimension had lowest mean value $(60.00 \pm 3.10)$ (25), that was in accordance with the results of this study. In this study, , there was a significant relationship between the four dimensions of physical, mental, time and effort, that shows nursing is not just a one-dimensional job, and everyone must understand the different dimensions of the profession and have the ability to coordinate these various features while doing their duties properly. In the study by Sarsangi et al., there was a meaningful relationship between all dimensions of workload that verifies the results of this study (26).

In the present study, there was not significant relationship between any of the demographic variables of different employment groups such as work experience, marital status, gender and work section with work load that can be due to lack of proper understanding of nursing and different dimensions of work. In the research of Sarsangi et al., there was a significant relationship between work-retardation and frustration with work experience, and age with mental workload, frustration, physical effort and physical requirement, which does not have compatibility with the results of this study (26).

In the study by Mohebbi far et al. in Qazvin City, $21.3 \%$ of the subjects had high levels of stress, $74.1 \%$ had moderate stress and $4.6 \%$ had low stress (27). Similarly in the present study, most people had moderate stress levels (68.78\%) due to difference in work condition.

The normal stress in most nurses can be due to the good communication and interaction between nurses and head nurses, which creates a relatively quiet and stressless environment among nurses. Besides, there was no significant relationship between demographic variables (sex, marital status, work experience, service section and employment status) with job stress $(P>0.05)$. However, the average stress in women was more than men, which could be due to physiological and mental differences between women and men, as well as social status and dual duties as housewives and employees for women. In a study by Arab et.al in Qom City, $84 \%$ of subjects had normal stress that was consistent with the results of this study (28). Emergency nurses had the highest stress levels in comparison to other personnel, which can be due to special working conditions and stressfulness of this department.There was no significant relationship between the severity of job stress and the demographic characteristics of the studied 
population such as gender, age, work experience, type of employment, education level, work shift, and salary, which confirmed the results of this study.

The study of Arab et al. showed a significant correlation only between job stress and status of employment (28), but in the current study, there was not any significant relationship between them, which could be due to inadequate understanding of job stress by contractual staff. In many internal and external studies, workload is the most important factor in job stress $(9,11)$. Gholamnezhad et al. in their study on the causes of job stress in nurses highlighted the high workload as the second factor in job stress, which confirms the results of this study (29). There was a significant correlation between job stress and work load in the study of Aoki et al. (30), but based on the results of the current study and other studies (31), significant correlation between high workload and job stress was not found $(P=0.25)$.

The executive limitation was the interference between completing the information by nurses with the patient's treatment stages. Therefore, to reduce this limitation, completion of the questionnaire should be done when nurses have enough time to answer the questions. Further studies are recommended in large cities and different hospitals as well as for practitioners, surgeons and operating room technicians.

\section{Conclusion}

Regarding the results of this research, workload is relatively high among nurses, and educational courses can be suggested for familiarizing nurses with different aspects of nursing as a multidimensional profession. The other aim of these educational courses is increasing nurses' knowledge about their job which can reduce the workload and occupational injury and increase the efficiency and performance of nurses.

\section{Acknowledgement}

We are grateful to the management of Vasei Hospital, Sabzevar City, and the head nurses of the departments for technical support, and also to all the nurses who participated in this study.

\section{Conflict of interests: None declared.}

\section{Reference}

1- Holmes S. Work rela ted stress a brief review. J R Soc Promot Health 2001; 121(4):230-5.

2- Duffield C, Roche M, Merrick ET. Methods of measuring nursing workload in Australia. Collegian 2006; 13(1):16-22.
3- Workload [Internet]. 2018 Jun. Available from: https://www.techopedia.com/definition/13544/workl oad

4- lacovides A, Fountoulakis KN, Kaprinis S, Kaprinis $\mathrm{G}$. The relationship between job stress, burnout and clinical depression. J Affect Disord 2003; 75(3):209-21.

5- Hamim N. Workload and work stress on caring behavior in nurse on nursing services. International Journal of Human Resource Studies 2015; 5(3):148-60

6- Kittrell Chitty K. Professional nursing concepts \& challenges. $4^{\text {th }}$ ed. Amsterdam, Netherlands: Elsevier Science Health Science div; 2004.

7- Vivienne W, Haines T. Workload and occupational stress in nursing. Can J Nurs Res 1989; 21(3):4958

8- McVicar A. Workplace stress in nursing: a literature review. J Adv Nurs 2003; 44(6):633-42.

9- Lotfizadeh M, Noor-hassim I, Habibi A. Analysis of occupational stress and the related issues among employees of Esfahan steel company (ESCO), Iran (2009). Journal of Shahrekord University of Medical Sciences 2011; 13(5):37-45

10- Gillies DA. Nursing management: a systemic approach. Philadelphia, United States: Walter Burns Saunders Co; 1994. P.48

11- Soori H, Rahimi M, Mohseni H. Association between job stress and work-related injuries: a case-control. Iranian Journal of Epidemiology 2006; 1(3-4):53-8.

12- Malekpour F, Mohammadian Y, Malekpour AR, Mohammadpour Y, Sheikh Ahmadi A, Shakarami A. Assessment of mental workload in nursing by using NASA-TLX. Journal of Urmia Nursing and Midwifery Faculty 2014; 11(11):892-9.

13- Zakerian SA, Abbasinia M, Mohammadian F, Fathi A, Rahmani A, Ahmadnezhad I, et al. The relationship between workload and quality of life among hospital staffs. Journal of Ergonomics 2013; 1(1):43-56.

14- Al-Kandari F, Thomas D. Adverse nurse outcomes: correlation to nurses' workload, staffing, and shift rotation in Kuwaiti hospitals. Appl Nurs Res 2008; 21(3):139-46.

15- Andersson EM, Hallberg IR, Edberg AK. Nurses' experiences of the encounter with elderly patients in acute confusional state in orthopaedic care. Int J Nurs Stud 2003; 40(4):437-48.

16- Rafiee N, Hajimaghsoudi M, Bahrami MA, Ghasemi N, Mazrooei M. Evaluation nurses' mental work load in emergency department: case study. Quartely Journal of Nursing Management 2015; 3(4):43-50.

17- de Jong $A E$, Leeman J, Middelkoop $E$. Development of a nursing workload measurement instrument in burn care. Burns 2009; 35(7):942-8.

18- Myny D, Van Hecke A, De Bacquer D, Verhaeghe $S$, Gobert M, Defloor T, et al. Determining a set of measurable and relevant factors affecting nursing workload in the acute care hospital setting: a cross sectional study. Int J Nurs Stud 2012; 49(4):42736.

19- Mohammadi M, Mazloumi A, Nasl Seraji J, Zeraati $\mathrm{H}$. Designing questionnaire of assessing mental workload and determine its validity and reliability among ICUs nurses in one of the TUMS's hospitals. Journal of School of Public Health and 
Institute of Public Health Research 2013; 11(2):8796.

20- Sarabandi A, Hazarati H, Keykha M. Occupational Stress in Military Health Settings: A Questionnaire based Survey. International Journal of Hospital Research 2012; 1(2):103-8.

21- Hashemzadeh E, Aurangi M, Bahrehdar M. The relationship between job stress and mental health in a group of hospital employees in Shiraz. Iranian Journal of Psychiatry and Clinical Psychology 2000; 6(2-3):55-63.

22- Hart SG, Staveland LE. Development of NASATLX (Task Load Index): Results of empirical and theoretical research. Advances in Psychology 1988; 52(1):139-83.

23- Fallahi M, Motamedzade $M$, Heidarimoghadam R, Soltanian AR, Farhadian M, Miyake Sh, et al. Analysis of the mental workload of city traffic control operators while monitoring traffic density: A field study. Int J Ind Ergon 2016; 54:170-7.

24- Rubio S, Díaz E, Martín J, Puente JM. Evaluation of subjective mental workload: a comparison of SWAT, NASA-TLX, and workload profile methods. Appl Psychol 2004; 53(1):61-86.

25- Taheri MR, Khorvash F, Hasanzadeh A, Mahdavirad M. Assessment of mental workload and relationship with needle stick injuries among Isfahan Alzahra hospital nurses. Medical Journal of Mashhad University of Medical Sciences 2016; 58(10):570-7 .

26- Sarsangi V, Saberi HR, Hannani M, Honarjoo F, Salim Abadi M, Goroohi M, et al. Mental workload and its affected factors among nurses in Kashan province during 2014. Journal of Rafsanjan University of Medical Sciences 2015; 14(1):25-36.

27- Mohebbifar R, Kiaei MZ, Khosravizadeh O, Sadeghi T, Ahansazan $H$. Job stress and its related factors in nurses of Qazvin University of Medical Sciences. The Journal of Medical Education and Development 2015; 7(1):55-63.

28- Arab Z, Piri L, Arsalani N, Tabatabai Ghomshe F, Biglarian A. The correlation of workload and work ability with job stress in nursing staff. Journal of Health Promotion Management 2015; 4(1):21-30.

29- Gholam Nejad H, Nikpeyma N. Occupational stressors in nursing. Iran Occupational Health 2009; 6(1):22-7.

30- Aoki M, Keiwkarnka B, Chompikul J. Job stress among nurses in public hospitals in Ratchaburi province, Thailand. Journal of Public Health and Development 2011; 9(1):19-27.

31- Zheng $B$, Jiang $X$, Tien $G$, Meneghetti $A$, Panton ON, Atkins MS. Workload assessment of surgeons: correlation between NASA TLX and blinks. Surg Endosc 2012; 26(10):2746-50. 